\title{
Impact of Head Nurses' Supervision Practices on Quality of Work Life as Perceived by Staff Nurses
}

\author{
AHMED A. OSMAN, M.Sc.*; MAGDA A. ABD EL-FATTAH, D.N.Sc.** and OM HASHEM G. RAGAB, D.N.Sc.* \\ The Department of Nursing Administration, Faculty of Nursing, Sohag* and Cairo** Universities, Egypt
}

\begin{abstract}
Background: Head nurses' supervision practices has direct effect on working condition and the relation between supervisor and staff nurses that finally influence the quality of nurses' work life.
\end{abstract}

The Aim of the Study: To assess the impact of supervision practices on quality of work life as perceived by staff nurses.

Material and Methods: A descriptive correlational design was used

Setting: The study was conducted at Sohag University Hospital at Units of Medical, Surgical Departments and General Intensive Care. Convenient nurses' sample two hundred forty who work at selected hospital. Two tools were used: Supervision practices and quality of work life questionnaire.

Results: Study revealed that the highest percentage of participants perceived average level of quality of nursing work life, the high mean score quality of work life was related to work context. There was negative significant correlation between supervision practices and quality of work life.

Conclusion: Study concluded that head nurses' supervision practices have direct effect on quality of nurses work life. When head nurses improving work context and work life of staff nurses this lead to improving quality of work life.

Recommendations: Head nurses should improve the working conditions and making a supportive, friendly, and intimate environment for all the staffs, involving nurses in decision making and respecting their viewpoints. Supervisor should realize and pay attention to the physical and mental conditions of each nurse's staff.

Key Words: Nurses - Supervision practices - Quality of Work Life $(Q W L)$.

\section{Introduction}

INSUFFICIENT supervision of health professionals may be harmful to patients. While adequate supervision has a positive impact on patient pro-

Correspondence to: Dr. Ahmed A. Osman, E-Mail: ahmedwa3867@yahoo.com gress. Supervision helps nurses to appraise their practice, improve professional skills, these improving the standard of care for patients. It leads to improve in multi-disciplinary teamwork, enabling the establishment of clinical standards and improving the quality of service delivery. Non-supportive supervision has worse effect on staff nurses motivation as staff nurses report feeling that their efforts not noticed while their mistakes are pointed out immediately. More over the supervisor giving feedback for staff on their performance and the supervisor should respond to feedback from the supervisee about supervision pattern [1,2]

Supervision is the active process of guiding, directing and influencing the outcome of a person performance of an activity, providing guidance for achievement of task or activity, with initial guidance and periodic observation of the actual achievement of the task or activity [3]. Supervision is defined as the tool for direction or guidance, evaluation, and follows-up by the delegator for achievement of a task delegated to another worker; to watch over a particular activity or task being done by other people and ensure that it is carried out correctly [4]

Supervision practices may be direct or indirect supervision: The direct supervision pattern applied through face to face communication with the nurses, this can be exercised at the ward/unit level in the hospital or the working setting in which the supervisor must not talk too much or too fast and not give instruction in a haphazard way. While the indirect supervision is done by reviewing the records and reports of nurses and through written instructions or analyzing the progress reports to know the input of performance and the outcome of the work and their relation with each other [5] Supervision make a link between staff nurses in 
units and management through measures to ensure that nurses carry out their work effectively and help them to improve their competence. Supervision made as the point of human interconnection between health workers and the health system [1].

Head nurse as a supervisor should know when and how the task is to be done, what information should be collected, expected outcome, the time frame for reporting result, and when to measure staff performance to ensure compliance with standards, procedure, and policy [6]. Head nurses as a supervisor play main role in the success of health care organization by motivating, engaging, and retaining employees. Support by supervisor leads to several organizational outcomes, such as enhanced organizational commitment, job satisfaction, role clarity, and high job performance and reduced turnover intentions. Support of supervisors toward the subordinates may be including answering to staff nurses' questions, giving suggestions, and listening to staff nurses' problem and complaints, guiding career development. A high level of supervisor support is expected to improve nurses' Quality of Work Life (QWL) [7].

Quality of work life has become an important issue recently. This means that manager should provide high priority to the needs of human resources, if they want to survive and success in the current competitive market [8]. QWL improves staff's function and treat absenteeism and desertion and ultimately lead to an increase of organizational efficiency. Nursing managers should provide an attractive workplace environment with adequate supervision which can attract new nurses in addition to saving the existing staffs in organization [9]

(QWL) defined as a degree to which an employee is satisfied with personal and working needs through participating in the workplace while achieving the goals of the organization [10]. Quality of work life can be defined as an employee's satisfaction with working life. It shows the relationship between employees and their physical, social and economic work environment. It is a milt-dimensional concept and covers an employee's feeling about various dimension of work. These include the fair and adequate compensation, work conditions, participation in decision-making, organizational and interpersonal relation and work life balance [11]

QWL includes not only occupational factors such as salaries, job satisfaction, and interaction with coworkers but also other factors such as life situation and general feelings of wellbeing. It includes a number of factors including welfare and medical facilities, job security, job design, job description, career development plans, training, and improvement. QWL is a main demand for newly recruits employed and current staff retention within all organizations [12]. Nurses' dissatisfaction with their own work life can lead to problems such as job dissatisfaction, emotional exhaustion, burn out and job turnover. These factors would affect the quality of care given by staff nurses [13]

A supportive supervisor plays main role in providing hospital resources, rewards, and opportunities for staff nurses that improve the satisfaction of their fundamental needs at work. In addition, a supportive supervisor makes nurses feeling that the hospital also supports them and cares about their well-being. Finally, supportive supervisor contributes to providing opportunities and hospital resources to nurses and make them feel that the organization values their contributions and cares about their well-being, which may eventually improve QWL [14]

\section{Subjects and Methods}

\section{Research design:}

Descriptive correlational research design was utilized to conduct this study.

\section{Setting:}

The study was conducted at Sohag University Hospital at Medical Departments (270 beds) that include (General Medical, Tropical, during 2018 Coronary Care, Dermatology, Intermediate Care, Neurological, Cardiac Catheter, Chest and Dialysis Units), Surgical Departments (245 beds) that include (General Surgical, Vascular Surgical, Plastic Surgical and Urological Surgical Units) and General Intensive Care Unit that contains (10) beds.

\section{Subjects:}

Convenient sample $(\mathrm{n}=240)$ of staff nurses who working in Medical Departments, Surgical Departments and General Intensive Care Unit.

\section{Data collection tools:}

\section{Data were collected using two tools:}

Tool I: Head nurses' supervision practices questionnaire: This questionnaire was developed by Atwa [15] and modified by researcher, it includes two parts: First part: Includes staff nurse's demographic data as (age, gender, nursing qualifications, marital status and years of experience). Second part: The questionnaire consists of 6 items selfreported by staff nurses to measure supervision 
practices. The response was based on a five point's likert scale, ranged from (1) strongly agree to (5) strongly disagree.

Tool II: Quality of Work Life (QWL) questionnaire: This questionnaire was developed by brooks [16] and modified by researcher, it to assess the nursing work life of staff nurse. It contains 42 items in the following subscales: (A) Work life/ home life (7 items), (B) Work design contain (10 items), (C) Work context (20 items), and (D) Work world (5 items). The response was based on a five point's likert scale, ranged from (1) strongly disagree to (5) strongly agree. The total score of the quality of nursing work life scale (230) was divided in to three levels as follow: (42-84) low QWL, (85-126) average QWL, (127-210) high QWL.

\section{Validity and reliability:}

Content validity of the study tools was established by seven experts in nursing administration field. Alpha Cronbach's coefficient test result for modified quality of nursing work life questionnaires was 0.87 and for supervision practices questionnaire was 0.90 .

\section{Pilot study:}

A pilot study was conducted on $10 \%$ of total number of nurses (24) which are excluded from the sample of the study to investigate and measure the feasibility, objectivity, applicability, clarity, adequacy of the study tools and to determine possible problems in the methodological approach or instrument. Based on the pilot study analysis minor modifications were done.

\section{Data collection procedures:}

The researcher had met the staff nurses on daily bases either as individually or in small groups during morning, evening and night shifts to distribute questionnaires for them, explained how to fill each questionnaire, meeting with each staff and filling the self-reporting questionnaires took from 10-20 minutes, data were collected from units of Medical Department that includes (General Medical, Tropical, Coronary Care, Dermatology, Intermediate Care, Neurological, Cardiac Catheter, Chest and Dialysis Units), Units of Surgical Department that includes (General Surgical, Vascular Surgical, Plastic Surgical and Urological Surgical Units) and General Intensive Care Unit. Data were collected from (March 2018 to September 2018).

\section{Ethical considerations:}

An approval to conduct the current study was obtained from the Ethical Committee at the Faculty of Nursing, Cairo University. Written informed consent was obtained after taken initial acceptance from research ethical committee, as well as official approval was obtained from president of Sohage University for data collection. Participation in the study was voluntary and based on the staff nurses agreement to give informed consent. Informed consent signed by participants after reading all of its details. The ethical issue considerations included explaining the purpose and nature of the study.

Participants had complete right to withdraw at any time without adverse impact on them and also obtaining the study results after its completion. Confidentiality maintained as the information was coded using initials or numbers and used only for the research purpose. After data was collected from staff nurses the final approval litter was obtained from Ethical Committee, Faculty of Nursing, Cairo University to confirm that all participants were accepted to participate at this study based on their informed consent.

\section{Statistical analysis:}

Up on completion of data collection the data were scored, tabulated and analyzed through data entry and analysis by computer using the Statistical Package for Social Science (SPSS) Version 20. Data were analyzed using the descriptive statistics in the form of frequencies distribution, percentages, means and standard deviations. Also the form of significance such as Pearson correlation coeffient. The $p$-value $>0.05$ indicate non significance result while, the $* p$-value $<0.05$ is significant and the $* * p$-value $<0.01$ is highly significant.

\section{Results}

Table (1): Revealed that, the majority of the respondents $(82.5 \%)$ were females, $(70.0 \%)$ married, $(64.6 \%)$ aged from 20 to less than 25 years and $(60.8 \%)$ of them were had less than 5 years' of hospital experience, $(47.5 \%)$ hold diploma degree in nursing.

Table (2): Showed the study participants perception of supervision practices items, the study revealed that $(39.2 \%)$ of participants was strongly agree on the item "supervisor focus on work error not to positive points" and (29.6\%) was strongly agree on the item "absence of useful discussion with supervisors". While $(60 \%)$ of participants was agree on the item "the supervisor doesn't share the nurses in decision making related to work". On the other hand $(39.6 \%)$ of participants was disagree on the item "supervisor assigns work of nurses unfairly" and (30.8\%) was disagree on the item "supervisors criticizes malpractice of nurses in front of patients and their colleagues". 
Table (3): Viewed that the highest mean and standard deviation of nurses' quality of work life were in work context $(57.49 \pm 13.61)$, followed by work design (28.32 \pm 6.37$)$. The lowest mean and standard deviation of nurses' quality of work life were in work life $(15.84 \pm 6.52)$ and work world dimension (13.89 \pm 3.94$)$.

Fig. (1): Illustrated that majority (65\%) of participants had average level of quality of nursing work life, while $(26.6 \%)$ of participants had high level of quality of nursing work life, also the minority $(8.3 \%)$ of participants had low level of quality of nursing work life.

Table (4): Indicated that there was negative significant correlation between supervision practices and total quality nursing of work life ( $r=$ $\left.-0.160^{*}, p=0.013\right)$.
Table (1): Percentage distribution of studied participants' demographic data $(n=240)$.

\begin{tabular}{|c|c|c|c|}
\hline \multirow{2}{*}{$\begin{array}{l}\text { Demo- } \\
\text { graphic } \\
\text { items }\end{array}$} & \multirow{2}{*}{ Variables } & \multicolumn{2}{|c|}{ Study sample } \\
\hline & & No. & $\%$ \\
\hline Gender & $\begin{array}{l}\text { - Male } \\
\text { - Female }\end{array}$ & $\begin{array}{l}42 \\
198\end{array}$ & $\begin{array}{l}17.5 \\
82.5\end{array}$ \\
\hline Age & $\begin{array}{l}\cdot 20 \text { to }<25 \text { years } \\
\cdot 25 \text { to }<30 \text { years } \\
\cdot 30 \text { to }<35 \text { years } \\
-\geq 35 \text { years }\end{array}$ & $\begin{array}{l}155 \\
64 \\
10 \\
11\end{array}$ & $\begin{array}{l}64.6 \\
26.7 \\
4.2 \\
4.6\end{array}$ \\
\hline $\begin{array}{l}\text { Marital } \\
\text { status }\end{array}$ & $\begin{array}{l}\text { - Single } \\
\text { - Married }\end{array}$ & $\begin{array}{l}72 \\
168\end{array}$ & $\begin{array}{l}30.0 \\
70.0\end{array}$ \\
\hline $\begin{array}{l}\text { Educational } \\
\text { level }\end{array}$ & $\begin{array}{l}\text { - Holding nursing diploma } \\
\text { - Diploma specialization } \\
\text { - Holding bachelor degree in } \\
\text { nursing }\end{array}$ & $\begin{array}{l}114 \\
99 \\
27\end{array}$ & $\begin{array}{l}47.5 \\
41.3 \\
11.3\end{array}$ \\
\hline $\begin{array}{l}\text { Hospital } \\
\text { experience }\end{array}$ & $\begin{array}{l}-1 \text { to }<5 \text { years } \\
\text { - } 5 \text { to }<10 \text { years } \\
\text { - } 10 \text { to }<15 \text { years } \\
\text { - } 15 \text { years and more }\end{array}$ & $\begin{array}{l}146 \\
41 \\
42 \\
11\end{array}$ & $\begin{array}{l}60.8 \\
17.1 \\
17.5 \\
4.6\end{array}$ \\
\hline
\end{tabular}

Table (2): Percentage distribution of the studied participants' perception of supervision practices items $(n=240)$.

\begin{tabular}{|c|c|c|c|c|c|c|c|c|c|c|}
\hline \multirow{2}{*}{ Supervision practices items } & \multicolumn{2}{|c|}{$\begin{array}{l}\text { Strongly } \\
\text { disagree }\end{array}$} & \multicolumn{2}{|c|}{ Disagree } & \multicolumn{2}{|c|}{ Uncertain } & \multicolumn{2}{|c|}{ Agree } & \multicolumn{2}{|c|}{$\begin{array}{l}\text { Strongly } \\
\text { agree }\end{array}$} \\
\hline & No. & $\%$ & No. & $\%$ & No. & $\%$ & No. & $\%$ & No. & $\%$ \\
\hline 1- Supervisor focus on work error not to positive points. & 10 & 4.2 & 40 & 16.7 & 65 & 27.1 & 31 & 12.9 & 94 & 39.2 \\
\hline 2- Absence of useful discussion with supervisors. & 32 & 13.3 & 63 & 26.3 & 64 & 26.7 & 10 & 4.2 & 71 & 29.6 \\
\hline $\begin{array}{l}\text { 3- The supervisor doesn't share the nurses in decision making related } \\
\text { to work. }\end{array}$ & 3 & 1.3 & 10 & 4.2 & 21 & 8.75 & 144 & 60 & 32 & 13.3 \\
\hline 4- Supervisor assigns work of nurses unfairly. & 10 & 4.2 & 95 & 39.6 & 53 & 22.1 & 30 & 12.5 & 52 & 21.7 \\
\hline 5- Feeling that supervisor have excessive desire to control of other. & 10 & 4.2 & 41 & 17.1 & 84 & 35.0 & 54 & 22.5 & 51 & 21.3 \\
\hline $\begin{array}{l}\text { 6- Supervisors criticizes malpractice of nurses in front of patients } \\
\text { and their colleagues. }\end{array}$ & 10 & 4.2 & 74 & 30.8 & 52 & 21.7 & 53 & 22.1 & 51 & 21.3 \\
\hline
\end{tabular}

Table (3): Mean and standard deviation of quality of nursing work life dimensions $(n=240)$.

\begin{tabular}{lc}
\hline Quality of nursing work dimensions & Mean + SD \\
\hline Work life & $15.84 \pm 6.52$ \\
Work design & $28.32 \pm 6.37$ \\
Work context & $57.49 \pm 13.61$ \\
Work world & $13.89 \pm 3.94$ \\
\hline
\end{tabular}

Table (4): Correlation between supervision practices and quality of work life $(n=240)$.

\begin{tabular}{|c|c|c|}
\hline \multirow{3}{*}{ Supervision practices } & \multicolumn{2}{|c|}{ Quality of nursing work life } \\
\hline & $r$ & $p$-value \\
\hline & $-0.160 *$ & 0.013 \\
\hline
\end{tabular}

*: Significant at $(p<0.05)$.

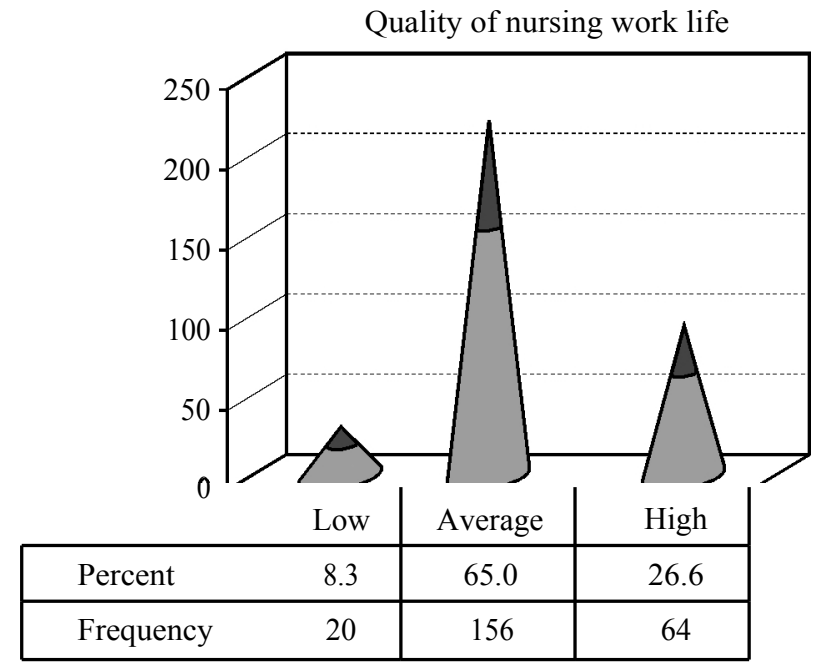

Fig. (1): Quality of nursing work life level $(n=240)$. 


\section{Discussion}

Quality of working life is normally including many dimensions as employee salary, facilities, health and safety issues, participating in decision making, management approach and job diversity and flexibility. Therefore, there is widely agreement that a major duty of any head nurses is to evaluate and improve the quality of nurses' working life by monitoring their work environment and knowing their possible shortcomings [17].

Regarding the demographic data of staff nurses the results showed that more than three-quarters of the participants were females, and more than two-third of the participants were married, aged from twenty to less than twenty five years and were had less than five years' experience in the hospital. Slightly less than half of them were hold diploma degree in nursing. This could be due to the fact that male enrollment in nursing program is considerably recent in Egypt. These results supported by Faraji et al., [12] study of the relation between nurses' quality of work life with intention to leave their job who reported that majority of the subjects were females and more than half of participants $(57.3 \%)$ were married.

As for supervision practices, the study results revealed that more than one quarter of participants was strongly agree on "absence of useful discussion with supervisors". While two thirds of staff nurses of participants was agree on "the supervisor doesn't share the nurses in decision making related to work", on the other hand less than half of staff nurses was disagree on "supervisor assigns work of nurses unfairly and more than one third of staff nurses was disagree on "supervisors criticizes malpractice of nurses in front of patients and their colleagues". This may be caused by bad supervision practices used by head nurses. These study findings supported by Suresh [18] who illustrated that the percentage of nurses who are communicating with nurse manager/supervisor was only more than half of participants. Thus half or more work in a setting in which they do not feel respected or rewarded by their supervisors.

In the same point the findings congruent with Eslamia et al., [9] who reported that lack of managers' supervision, participation in decision making, feedback and higher level of managers' respect toward nurses. More than half of nurses believed they were not able to communicate with their supervisors and nurse managers. On the other hand the study finding inconsistent with Alzalabani [8] who reported that two thirds of participants agreement was on supervisor encourages employee to participate in decision-making, while it was consistent in that supervisor treats workers fairly and equitably.

The present study findings viewed that the highest mean and standard deviation scores of nurses' quality of work life were in work context followed by work design and the lowest mean and standard deviation scores were in work world dimension. From the research point of view these results may due to poor management and negative supervision practices. These study finding agreement with Eslamian et al., [9] who showed that work context had high mean and standard deviation scores, while work life/home life and work world dimension had low mean and standard deviation scores. In the same line Suresh [18] reported that work context had high mean and standard deviation scores, while work design and work life-home life had the low mean and standard deviation scores. In the same point the finding compatible with Morsy and Sabra [19] who showed that the high mean score was related to work context, while low mean score was related to work life/home life dimension.

The study results revealed that more than two thirds of participants had average level of quality of nursing work life, while only more than one quarter of participants had high level of quality of nursing work life. This may be because imbalance between work life and family needs also may cause by incongruent between nurses and head nurses. These study findings consistent with Jembere [20] who showed that the majority of the study participants had moderate quality work life score. It is only four percent of participants had good quality of work life. In the same line Fasla [21] reported that majority of the participants have moderate level of quality of work life. The study findings incompatible with Faraji et al., [12] who revealed that the work life quality level in two thirds of the nurses were low, more than one third of them experience moderate QWL, and one percent experience high QWL.

The study results indicated that there was negative significant correlation between supervision practices and total quality of nursing work life. This may due to the all items of supervision practices was negative that lead to bad effect and decrease in the quality of work life these finding congruent with Penny and Joanne [14] argued that negative supervision lowering the quality of work 
life level and a supportive supervisor help to enhancing employees' QWL. In the same line Rathi and Lee [7] demonstrated that the supervision pattern is significant affecting the quality of work life.

\section{Conclusion:}

The present study findings revealed that there was negative significant correlation between supervision practices and total quality nursing of work life. The highest percentages of the participants had less than 5 years' experience in the hospital, and hold diploma degree in nursing. Supervisors focus on work errors not positive points, ineffective communication and lack of participation in decision making, while there was fair work assignment and supervisors didn't criticize male practice in front of others.

More than two thirds of participants had average level of quality of nursing work life. The results viewed that the highest mean and standard deviation of nurses' quality of work life were in work context, work design and the lowest were in work life dimension respectively.

\section{Recommendations:}

- Head nurses as a supervisor should focus on positive points of staff nurses and struggle to control and correct nurses' errors through positive supervision to involve staffs.

- Also should consider improvement of working conditions by involving nurses in decision making, respecting their viewpoints, and participate with their ideas.

- Establishing two-way communication by improving nurse supervisor discussion with subordinates, and colleagues at work.

- Training program for supervisor nurses should be developed and implemented.

\section{References}

1- HERNÁNDEZ R.A., HURTIG A., DAHLBLOM K. and SEBASTIÁN S.M.: More than a checklist: A realist evaluation of supervision of mid-level health workers in rural Guatemala, Bio. Med. Central Ltd, 2014.

2- MARTIN R., COPLEY J. and TYACK Z.: Twelve tips for effective clinical supervision based on a narrative literature review and expert opinion, Medical Teacher, 2014.

3- FINKELMAN A.: Leadership and management for nursing, Third edition, Boston, Pearson, Pp. 413, 2016.
4- PORTER O., GRADY T. and MALLOCH K.: Leadership in nursing practice, Third edition, Burlington, Jones \& Bartlett Learning, Pp. 433, 2016.

5- BASAVANTHAPPA B.T.: Nursing administration, third edition, New Delhi, Jaypee Brothers Medical Publishers, Pp. 347-50, 2014.

6- KELLY P.: Nursing leadership \& management, Third edition, United States of America, Thomson Delmar Learning, Pp. 345-6, 2012.

7- RATHI N. and LEE K.: Understanding the role of supervisor support in retaining employees and enhancing their satisfaction with life, Personnel Review, Vol. 46 Issue: 8, Pp. 1605-19, 2016.

8- ALZALABANI H.A.: A Study on Perception of Quality of Work Life and Job Satisfaction: Evidence from Saudi Arabia. Arabian Journal of Business and Management Review. Volume 7, Issue 2, 2017.

9- ESLAMIAN J., AKBARPOOR A.A. and HOSEINI A.S.: Quality of work life and its association with workplace violence of the nurses in Emergency Departments. Iranian Journal of Nursing and Midwifery Research, Vol. 20, Issue 1, 2015.

10- SIRIN M. and SOKMEN S.: Quality of Nursing Work Life Scale: The Psychometric Evaluation of the Turkish Version. International Journal of Caring Sciences, 8 (3): Pp. 543-54, 2015.

11- AHMED E.: Quality of work life as perceived by staff nurses and its relation to the turnover intention at critical care units. M.D. Thesis, Faculty of Nursing, Cairo University, Egypt, 2015.

12- FARAJI O., SALEHNEJAD G., GAHRAMANI S. and VALIEE S.: The relation between nurses' quality of work life with intention to leave their job, Nurse Pract. Today, 4 (2): Pp. 103-11, 2017.

13- MORADI T., MAGHAMINEJAD F. and AZIZI-FINI I.: Quality of Working Life of Nurses and its Related Factors. School of Nursing and Midwifery, Tehran University of Medical Sciences, Tehran, IR Iran, 3 (2): Pp. 1-6, 2014.

14- PENNY and JOANNE: Casino employees' perceptions of their quality of work life, International Journal of Hospitality Management, Vol. 34, September, pp. 34858, 2013.

15- ATWA A.: The effect of workload on nurse's error. M.D. Thesis, Faculty of Nursing, Zagazig University, Egypt, 2002.

16- BROOKS B.: Development of an instrument to measure quality of nurses" "Work life. University of Illinois at Chicago: Health Sciences Center. Ph.D. Thesis, 2001.

17- BATTU N. and CHAKRAVARTHY K.: Quality of work life of nurses and paramedical staff in hospitals. International Journal of Business and Administration Research Review, Vol. 2, Issue 4, 2014.

18- SURESH D.: Quality of Nursing Work Life among nurses working in selected government and private hospitals in Thiruvananthapuram. M.D. thesis, Achutha Menon Centre for Health Science Studies Sree Chitra Tirunal Institute for Medical Sciences \& Technology Thiruvananthapuram, Kerala, 2013. 
19-MORSY M.S. and SABRA E.H.: Relation between quality of work life and nurses job satisfaction at Assiut University Hospitals. Vol. 13, No. 1, 2015.

20- JEMBERE W.: Assessment of quality of work life an associated factors among nurses working in public hospi- tals of Addis Ababa. MD thesis, College Of Health Science, Addis Ababa University, Ethiopia, 2015.

21- FASLA N.P.: A Study on Quality of Work life among Private Hospital Nurses with Special Reference to Mannarkkad Municipality, Palakkad District, 2017.

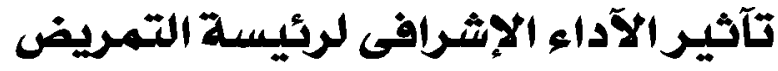

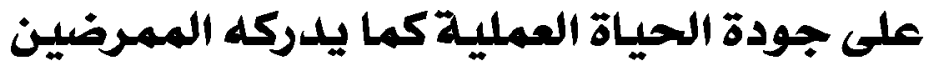

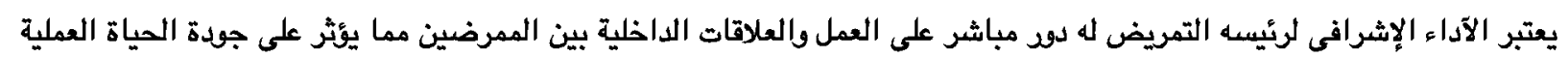

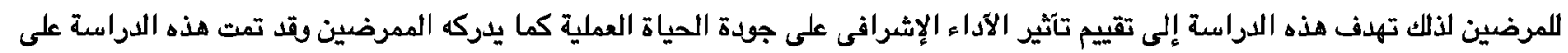

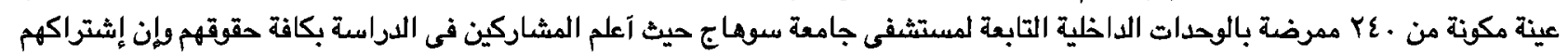

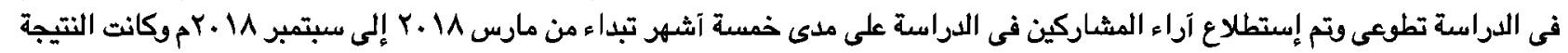

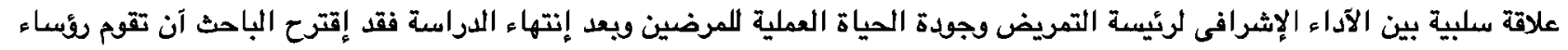

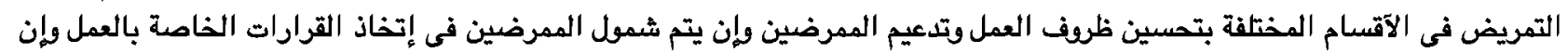

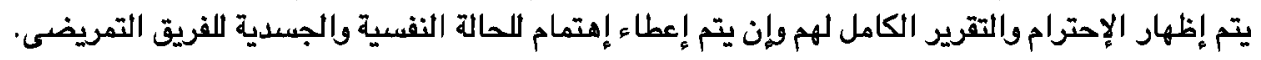

